\title{
Study and Translation of Sun Tzu's Art of War in Recent Years
}

\author{
Jingna Qiu ${ }^{1} \&$ Jingyuan Zhang ${ }^{1}$ \\ ${ }^{1}$ School of Foreign Studies, University of Science and Technology Beijing, Beijing, China \\ Correspondence: Jingyuan Zhang, Mail Box 789, School of Foreign Studies, University of Science and \\ Technology Beijing, No.30 Xueyuan Road, Haidian District, Beijing, China. E-mail: zhangjingyuan@263.net
}

Received: May 31, 2017

doi:10.5539/ass.v13n8p146
Accepted: June 14, $2017 \quad$ Online Published: July 25, 2017

URL: https://doi.org/10.5539/ass.v13n8p146

\begin{abstract}
Increasing more studies and translations of Sun Tzu's Art of War which is one of the leading military masterpieces around the world has been witnessed in recent years. This paper reviews the translation by Sawyer, Minford, Lin and Huang to probe into the characteristics and mistranslations within the framework of Context Theory in Systemic Functional Linguistics. It is found that Sawyer's translation excels in the recontextualization of context of culture with rich para-texts, Minford tends to interpret with western discourse, Lin excels in comparatively accurate understanding of the source text and Huang's translation merits in the recontextualization of language and military cultures.
\end{abstract}

Keywords: Sun Tzu's Art of War; translation; Context Theory; recontextualization

Works reviewed, in order of discussion:

Sawyer, R.D. The Art of War. Boulder: Basic Books, 1994.

Minford, J. The Art of War. New York: Penguin Group, 2002.

Lin Wusun. Sun Zi: The Art of War:Sun Bin: The Art of War. Foreign Languages Press, 2001.

Huang, J.H. The Art of War (SunTzu). New York: HarperCollins Publishers, 1993.

For more than 2,000 years, Sun Tzu's Art of War has been acknowledged as the most influential work on the art of warfare in China, which has been arousing worldwide interest especially in the Far East, like Japan, Korea and so on.

Unmatched importance attached to Sun Tzu and renewed attention paid to his masterpiece has been witnessed as Chinese cultural influence extended. Among numerous English versions translated by sinologists, literal translators, military strategists as well as entrepreneurs ever since artillery lieutenant E. F. Calthrop initiated the translation in the English language in 1905, there are four outstanding ones published in the last two centuries to be discussed in the present article, namely, that translated by Sawyer, Minford, Lin and Huang with the aim of providing few qualms and warnings and seeking self-reflection on the growing relevance to analysis of contemporary Chinese military thought and the revolution in military affairs.

\section{Ralph D. Sawyer: Being objective to the masterpiece}

Ralph D. Sawyer, a Harvard-trained sinologist, translator, and leading scholar in the field of Chinese warfare, has contributed to the translation, popularization and application of Sun Tzu's strategies.

What makes Sawyer outstanding in the history of translating Chinese classics is that he is the first to publish the English version of The Seven Military Classics of Ancient China in 1993, realizing that Sun Tzu alone cannot say all about the Chinese military wisdom, being epoch-making as no complete translation of ancient Chinese military collections was in sight before. In 1994, a separate edition of Sun Tzu's The Art of War was published and well received.

\subsection{Re-contextualization of the source text}

Unlike many other translators, Sawyer explores the deep connotation of controversial concepts like “詭道 Way of Deception” and “用間 using spies” with extremely earnest attitude. He argues that "deception and manipulation are actually aspects of the greater question of form (hsing) and the formless"(Sawyer, 1994, p.137) and points out that using spies should be discussed in the context of military strategies, and it is unreasonable for hypocritical Confucian literati to vilify that strategy as moral deficiency. 
Sawyer pointed out in the preface that in order to gain a better understanding of Sun Tzu's era, "it is worthwhile to reconstruct many facets of Spring and Autumn political and economic life" (Sawyer, 1994, p.85), hence his translation is far more than mere translated texts, but includes rich para-texts mounting to over 200 pages to re-contextualize the political situation, economic development, military organization and linguistic culture of source text.

For example, he briefly introduces the social stratification of Shang Dynasty and the feudal system of land-holding in Zhou Dynasty. In terms of economic background, he touches on the agricultural economy, the “井田制 nine squares” system (of land ownership in China's slave society), relates the bronze and metallurgy technology to the weaponry improvement and provides a brief discussion of the then economic situation and system of different states.

Sawyer's The Art of War is especially conspicuous in the introduction of military background information. He not only mentions the historical disturbance and turmoil but also gives a comparatively detailed account of Shang, Western Chou, Wu, Ch'u and Yüeh states. He exemplifies the application of Sun Tzu's strategies in the wars among Shang, Zhou and other states. Based on historical records, Sawyer depicts strategic layout and tactical map of battle of “雞父之戰 battle of Chi-fu” between Wu and Ch'u and that of “笠澤之戰 battle of Li-che river" between $\mathrm{Wu}$ and Yüeh.

Besides, Sawyer expounds the military culture in five aspects: firstly, the traces back the origin of ancient military thoughts and introduces the composition of the seven military classics of ancient China; then he accounts the warfare mode and tactics in Shang and the Warring States Period; he explicates the military organization of “軍 Chün”, “旅 lü”, “卒 tsu”, “伍 wu”, “師 shih” according to 周禮 Chou Li. He devotes separate sections to the explication of weapons like 戰車 Chariots, 驽 crossbows and main concepts like “仁 Benevolence”, “勢 Shih” and “五德 the five virtues of warfare” and so on.

\subsection{Domestication: say it in the western way}

Sawyer targets at a general readership, hence he adopts Domestication translation to adapt to the context of target language. He seeks for conceptual equivalence by replacing the source text with western terms familiar with the potential reader in order to improve the readability. Take the terms of measure and weight as an example, Sawyer tends to transliterate or use western replacement. He translates “裡 li/鐘 zhong/石 dan" into "Li”, "bushel” and "picul" respectively. See the following instance:

故勝兵若以鎰稱銖, 敗兵若以銖稱鎰（形篇）

(gu Shengbing ruo yiyichengzhu, baibing ruo yizhuchengyi)

Sawyer: Thus the victorious army is like a ton compared with an ounce, while the defeated army is like an ounce weighed against a ton!

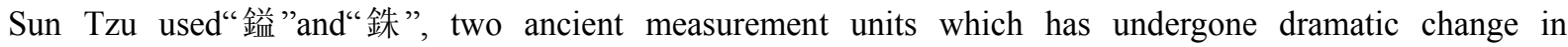
contemporary China to emphasize the discrepancy between winner and loser in warfare. Sawyer replaces them with "ton" and "ounce" to relieve the reading burden and cater to the cultural schema of the target reader.

However, too much westernization may turn out to be defective. Take the translation of core term "天 tian" as an instance, it is a philosophical concept in Sun Tzu's Art of War, referring to the natural or philosophical existence related to military meteorology or tactical organization with no touch of religious connotation. Sawyer replaces it with the western equivalence "Heaven", solving the problem of conceptual vacancy, but conjuring up the correlation with the Creator/God, the concept of soul and sin on the reader's part (Roger Ames, 2002, p.18). The additional religious flavor imposed on Sun Tzu deviates from the dialectical materialism of the source text.

Besides, Sawyer caters to the reader's expectancy by providing translations of others translators like Griffth, Giles, and Cleary and so on occasionally to facilitate inter-text comparison and improves the credibility of the translation itself.

\subsection{Foreignization: cultural equality and the Other}

From the translation of Sun Tzu to the explication of The Tao of Deception: Unorthodox Warfare in Historic and Modern China, Tao of Spycraft, Fire and Water: The Art of Incendiary and Aquatic Warfare in China and other writings concerning Chinese martial arts, Sawyer exhibits attitude of cultural equality and respect. Therefore, while translating Sun Tzu, he pays special attention to the concepts and terms unique to Chinese culture by integrating transliteration, annotation and other Foreignization approaches to enhance the semantic fullness and decrease the semantic loss in inter-lingual transformation.

For the core term 勢 Shi, Sawyer varies the translation according to the concrete context into "strategic military 
power (Shih)","strategic power" and "strategic configuration of power (Shih)", each with English equivalence and transliteration to decrease the semantic loss. Similarly, he translates 奇 Qi and 正 Zheng into "unorthodox (ch'i)" and "orthodox (cheng)"。

For the key philosophical term 道 Dao in pre-Qin history, Sawyer translates it into Tao or the form of "the Way (Tao) (to/for/of...)", with detailed annotation concerning the origin and connotation of it with evidence from Chinese Classics 道德經 Tao Te Ching and so on, in order to provide necessary supplement while solving the problem of untranslatability and keeping the exotic flavor of the term. This approach is repeatedly applied to the translation of “四帝 the four emperor”, “氣 Qi”, “霸王 hegemony” and other terms peculiar to Chinese.

However, too much Foreignization without annotations hinders the understanding. For example, Sawyer transliterates the philosophical term 陰陽 into “yin and yang" without any explication. For the general readership without special knowledge precipitation of ancient China, this translation is obviously inadequate.

\subsection{Linguistic aspect and misreading: inspect into the insider}

Translation assessment inevitably involves that of the linguistic aspect. Sawyer's translation of Sun Tzu deals well with semantic fullness, rhetoric restoration and lexical manipulation.

For most cases, he does word-to-word translation and provide supplement in square brackets to facilitate understanding, guarantee discourse coherence, add interlinear noting or parallelize the original modal particle while keeping the lines running smooth and reducing reading interference. The translation of “天地孰得 Tiandi Shu De" into "Who has gained [the advantages of] Heaven and Earth" is a proper case. Sawyer reads between the lines and digs out that the authentic object of 得 is the advantage of 天地, hence puts the exploitation in brackets to aid others' reading.

Sawyer does a lot of interlinear contextualization as well. For example, he translates Chi Che 馳車 and Fen Wen 䡩轀 into "four-horse attack chariots" and "armored assault wagons" respectively, emphasizing the structure, nature and offense application of them.

As for the rhetoric, Sawyer attempts to assemble the conciseness, rhythm and rhetorical approaches of the source text. He puts “fu bingjiu er guolizhe, weizhiyou ye 夫兵久而國利者, 未之有也” into “No country has ever profited from protracted warfare", with only eight words, being far simpler than Lin's "For there has never been a prolonged war from which a country has benefited"(Lin, 2001, p.13).

When it comes to metaphors, parallelism, anadiplosis and other modes of rhetoric, Sawyer tends to be faith to the original. For example, he translates “近師者貴賣, 貴賣則百姓財竭, 財竭則急於丘役 jinshizhe guimai, guimai ze baixing caijie, caijie ze jiyu qiuyi" into "Those in proximity to the army will sell their goods expensively. When goods are expensive, the hundred surname's wealth will be exhausted. When their wealth is exhausted, they will be extremely hard pressed [to supply] their village's military impositions". By imitating the anadiplosis, the translated text exhibits the interlinear logic between inflation of prices, impoverishment of the folk and urgency to warfare clearly.

The lexical treatment is worth mentioning as well. Take “故用間有五: 有因間, 有內間, 有反間, 有死間, 有生間”, 提到因間、內間、反間、死間和生間 gu yongjian youwu: you yinjian, you neijian, you fanjian, you sijian, you shengjian" as an example, Sawyer translates it into "Thus there are five types of spies to be employed: local spy, turned spy [double agent], dead [expendable] spy, and the living spy". Relating 反间 and 死间 to double agent and expendable spy respectively is refreshing and eye-catching. He puts “不竭如江河 bujie ru jianghe" into "as unlimited as the Yangtze and Yellow rivers", adding sort of exotic flavor by specifying rivers to the symbolic river of China.

Despite the rigorous academic exploration of the source text, deviations and misreading exist in Sawyer's translation, mainly in misreading of core terms and break of cultural convention. Sawyer translates “分數 fenshu", a military term unique to Sun Tzu, referring to the organization approach of organizing and managing soldiers in different classification, entailing the effect of managing a large number of soldiers the same as that of few soldiers, into "a question of dividing up the numbers", hence hinders the accurate understanding of the source text. Instead, "a matter of organization" may cater to the cultural logic better. For cultural convention, Sun Tzu has a famous saying “是故朝氣銳, 書氣惰, 暮氣歸; 故善用兵者, 避其銳氣, 擊其惰歸, 此治氣者也”, in which“朝/書/暮”has undergone dramatic change in meaning. The original referring to timing has been converted to symbolize the beginning, duration and ending of certain periods. But Sawyer still translates them into "in the morning/during the day/at dusk", which clearly violates the cultural convention of Sun Tzu.

Of course, the flaws do not detract from the jade's essential beauty. Sawyer's translation of Sun Tzu is comparatively advantageous in the scrupulously supplemented contextualization and agile integration of 
Domestication and Foreinization as well as semantic fullness and modernized lexical manipulation.

\section{John Minford: Interpreting Sun Tzu with western discourse}

John Minford, a sinologist and literary translator, has been an experienced translator of Chinese classics, including the last 40 chapters of Hongloumeng together with sinologist and his father-in-law David Hawkes, Louis Cha's The Deer and the Cauldron and a selection of Pu Songling's Strange Tales from a Chinese Studio, The Art of War and I Ching.

Minford embarks on the translation of Sun Tzu's Art of War at the invitation of Penguin Group, and published the translation in 2002, warmly received and appreciated for the simple wording and resembling rhythm of the source text, which leads to the necessity of reviewing the work in this article.

\subsection{Scaffolding the reader: contextualization and reader-consciousness}

To avoid interfering with the reading, Minford creatively separates his version into three parts, i.e. pre-text introduction to re-contextualize Sun Tzu and his work, translated text itself without any notes or annotations to provide unadorned reading experience of the original culture and translation with annotations for further explanations.

Minford applies rich para-texts to provide background information about Sun Tzu, the translation itself, pronunciation and reference suggestion in roughly 60 pages. But unlike Sawyer's objective contextualization, Minford tends to express personal judgment, guiding the reading perspectives of the potential reader.

While introducing the Spring and Autumn period, Minford studiously emphasizes the then turmoil and tangling situation. He briefly accounts the arrows, chariots and other weapons; provides the basic information of Sun Tzu and Sun Pin; exemplify core concepts like 勢 shi; Lists the names of annotators of Sun Tzu like Caocao, Zhangyu and many others; and offers a list of chronology of Chinese dynasties as well. Besides, Minford mentions historical personage Zhuge Liang (the Sleeping Dragon), litterateur Liu Xie and Ouyang Xiu, great thinkers Confucius, Mencius and Chinese Classics like The Book of Changes, The Romance of the Three Kingdoms and so on to reconstruct the diachronic context of the source text.

Minford applies 1,100 pieces of annotations and running commentaries for further contrast and explanation, mainly in three categories. Firstly, listing or citing from over 15 Chinese Classics including The Book of Mencius, The Book of Lord Shang, Record of the Grand Historians, The Book of Zhuangzi, The Zuo Commentary; then, listing or quoting the views of over 16 ancient and contemporary Chinese annotators and scholars of Sun Tzu; Minford cites the translation of other translators, like Giles, Roger Ames, Griffth and Jean Lévy and so on.

Besides, Minford adds 125 pieces of translator notes to provide further explain, contrast and personal comment concerning eight categories, i.e. brief introduction of core terms like “道 dao”“陰陽 yin yang” and “勢 shi”; synopsizing Proper Names like “诸侯 zhu hou” and “吕牙 lü Ya”; making contrast between the Song version and unearthed Yinqueshan bamboo strips in Han tombs; validating the translation wording; commenting on the source text; summarizing main points of a certain chapter; criticizing views of other scholars and expounding cultural connotations of certain terms.

For example, Minford claims that he cares less about the concrete numbers appearing in Sun Tzu, but focuses on the discrepancy indicated by them, hence he even translates “百里”、“五十裡”和“三十裡” into “Thirty miles/fifteen miles/ten miles".

Objectively speaking, Minford's endeavor to resort to a hotchpotch of resources for explanation eases the reading burden to a great extent by reconstructing the historical and social background of Sun Tzu and his masterpiece, but with occasional ineffective or defective analogy in the annotations. For example, at the first appearance of key term 道 dao in the first chapter, Minford juxtaposes the line “譬道之在天下, 猶川谷之于江 海 All under heaven will be drawn to the Way, as streams and torrents flow into a great river or sea" (Minford, 2002, p.102) there without any explanation, which may lead to confusion between core concepts in Sun Tzu and The Way and Its Power.

\subsection{Analogizing between Orient and Occident}

With a general western readership as the target, Minford caters to the reading expectancy and cultural psychology through annotating and analogizing the Orient with the Occident.

For example, Minford points out that Sun Tzu’ saying “投之亡地然後存, 陷之死地然後生 Plunge them into death ground, and they will live"(Minford, 2002, p. 298) resembles the western saying "Nothing ventured, nothing gained" to activate the cultural schema of the potential reader. 
When it comes to tactical strategies or maneuver tactics, Minford tends to make analogies with those practiced by western military elites, such as Napoleon, Caesar, Marlborough and Wellington. Besides, numerous western battles like the battle of Waterloo, the Gallic wars and the battle of the river Trebbia, military works like Clausewitz's On war and World History of the Art of War, and figures and historical events from the western world like England poet Edward Young, drama Tyrannic Love, philosopher Angus Charles Graham, Greece historian Polybius, French sociologist and sinologist Marcel Granet are cited or briefly mentioned to relieve the readers from struggling with pure Oriental events and thought.

With respect to other translators, Minford cites and quotes Giles for over 130 times, praising Giles' translation as one being able to stand the test of time admirably, standing out in at least three aspects, namely the referring to western figures like Greece writer and historian Herodotus and Thucydides, Roman history Livy, American general Baden-Powell, Stonewall Jackson, Hannibal, Napoleon and so on; the appropriate dealing with military terminology and the expanded annotation and criticism of Sun Tzu.

\subsection{Adapting the language: Linguistic simplification and rewriting}

While attempting to keep faithful to the original content, Minford makes adjustment and rewriting of the language to satisfy the literate necessity of general readership, mainly in four ways, i.e. decrease the linguistic difficulty by application of nominalization, rewrite certain situations to make it more narrative-like, switch the narrative perspective to enhance interactivity and adjust cohesive devices to enhance coherence and cohesion of the discourse.

Take the high frequency construction of 者 $z$ he for example, Minford translates them into noun groups like "The Skilful Warrior/A Skilful Defender/A Skilful Attacker/The Skilful Warrior of old" instead of embedded clause like "one /those that [who excels at warfare/war/defense/in warfare]" applied by Sawyer and other translators, entailing comparative conciseness and relatively greater readability.

Minford changes certain situations to enhance the sense of narration. For example, he translates “土卒坐者涕沾 襟, 偃卧者涕交卧 Tears may soak the garments of those sitting and wet the faces of those lying down (Lin, 2001, p.89) " into "They sit up and weep, wetting their clothes with their tears; They lie down and weep, wetting their cheeks". The change of soldiers as protagonist into "he" as a sole leading role deviates from the original text, but through narrating the "story" around a single soldier, the translator depicts the sorrow and grief before battles vividly.

Simplification for readability can be acceptable, but oversimplification resulting in distortion of the source text is not. Minford translates “守则不足, 攻则有余” into “Defense implies Lack; Attack implies abundance”. Despite the seemingly conciseness of wording, the translation exhibits inadequacy in logic interpretation: defense is not necessarily due to lack and attack does not inevitably presuppose abundance, otherwise 分數 fen shu would not have existed.

Minford switches narrative perspectives and modulates the system of Modality to enhance the objective atmosphere and readability of the translated text. He applies the third singular abundantly while using few second person "you", to isolate the reader from the "story" and increase a touch of dedicative flavor. To consolidate the objectivity and conciseness, he switches some declarative clauses into imperatives and deletes certain modal verbs, which leads to deviations as well. For example, by putting “上下同欲者勝” into “Have officers and men who share a single will", deviation from "the party who can make the officers and men share a single will can be victorious" occurs.

The most conspicuous advantage claimed for Minford's translation may be the restoration of rhythm of the source text. He breaks the source text into different lines with the form similar to English poems to create a sense of rhyming, with frequent alliterative, end rhyme and internal rhyme. Take the translation of “帥與之期,如登高 而去其梯.帥與之深入諸侯之地,而發其機,焚舟破釜,若驅群羊,驅而往,驅而來,莫知所之”as an example.

He leads his men into battle

Like a man

Climbing a height

And kicking away the ladder;

He leads them

Deep into the territory

Of the feudal lords

And releases the trigger.

He burns his boats, 
He breaks his pots.

He is like a shepherd

Driving his sheep

This way and that;

No one knows

Where he is going.

Long and short clauses in different lines create a sense of rhyming. Besides, "shepherd" and "sheep" form the alliterative of $/ \delta /$; "releases/burns/breaks" forms end rhyme of $/ \mathrm{J} /$; "ladder" and "trigger" forms $/ \mathrm{\partial} / \mathrm{rhyme}$ and "boat/pots" creates /ts/ rhyme.

Minford excels at enhancing the dynamic description of situations through such adaptations, but with certain deviations due to excessive pursuit of formal equivalence to the source text. For instance, many connective words like “是故/故 therefore/hence" are deleted for the sake of conciseness and rhyme, resulting in the oversimplification of logico-semantic relations.

\subsection{Painful lesson: cultural misreading}

Minford claims that he is most satisfied with his translation of Sun Tzu and attempts to keep faith to the source text. But astonishingly, his para-texts overflow with cultural discrimination and misreading.

As mentioned previously, Minford tries to add personal interpretation instead of reconstructing the context objectively like Sawyer does. He misreads the concept of 詭道 and devotes two sections in the preface under the headline of "The Way of War is a Way of Deceptions" and "Cunning Plans, Popular Culture" to expound with the stories of Han Xin and the Sleeping Dragon to prove his false assumption that Sun Tzu uses 詭道 to deceive and make use of other people. As a matter of fact, 詭道 is a way of changing, just as Sawyer puts it in his work Tao of Spycraft, a way of varying approaches at the level of strategies instead of moral judgment, which is far from being "shocking" as Minford claims.

According to Minford, Sun Tzu is completely different from Confucianism in the attitude towards warfare. In fact, just as Confucius is against war and advocates benevolence and righteousness in war, Sun Tzu emphasizes the same by prudence on initiating wars in lines “亡國不可以複存,死者不可以複生 A vanquished state cannot be revived, the dead cannot be brought back to life”, preservation in “不戰而屈人之兵, 善之善者也 Subjugating the enemy's army without fighting is the true pinnacle of excellence" and “善而養之 Treat the captured soldiers well" and so on. Griffth once pointed out that Sun Xingyan is right in saying that Sun Tzu's theory is based on benevolence and righteousness.

Minford depreciates Legalism and equals it with Chinese Fascists, saying that Legalism abducts Daoism doctrines and deviates from the "Nature and Humanity" ideology. He analogizes Sun Tzu's Art of War with the sex book Wonderful Disquisition of the Plain Girl, hence vulgarizing and vilifying Chinese culture.

Direct sarcasm towards Chinese people and culture can be found in the annotations. For example, annotator Jia Lin lists ways of causing harms to the opposing army for “是故屈诸侯者以害”, while Minford quotes Giles that "some of the ways of inflicting this injury enumerated by Jia Lin would only occur to the Oriental mind" (Minford, 2002, p. 221). In the chapter of using spies, Giles comments that Chinese people are peace-loving, while Minford jots that "Gile's comment, though not of strict relevance or even necessarily true, is challenging and of considerable intrinsic interest... his idea, that the true object of war is peace, has its root in the national temperament of the Chinese"(Minford, 2002, p. 316).

As a whole, Minford's translation is advantageous in catering to the western world in analogizing the east with the west, excels at concise words and restoration of rhythm, but is far less faithful to the source text than Sawyer, and the cultural distortion outweighs the linguistic merits with possibilities of misleading the potential reader.

\section{Lin Wusun: Getting closer to the western reader}

Statistically, there have been more than 50 complete English translations ever since 1905, among which over 24 are done by Chinese translators, scholars and military researchers since Cheng Lin, a distinguished translator of ancient historical philosophy and pre-Qin classics, published his Sun Tzu's The Art of War plus The Ancient Chinese Revealed (Cheng, 1946). That work received limited circulation due to the coarse English proficiency criticized by many scholars including Giles who depreciated it as worthless (Griffth, 1963, p.182). Another three versions by Tao (1987), Yuan (1987) and Luo (1996) have been eye-catching as certain western readers expect Oriental-style interpretation.

The eagerness to let Sun Tzu say in his own words gives renewed impetus to the retranslation of the masterpiece 
funded by Chinese government, which leads to the publication of Sun Zi: The Art of War by Chinese translator Lin Wusun.

\subsection{Cultural mission: Say it with Sun Tzu's own words}

Classics are always open to interpretations, which may be confusing or misleading when deviation or vilifications are implicitly inflicted. To decrease such interference, Lin's translation attempts to get closer to Sun Tzu and let the work unfold as objectively as possible without glorification or exaggeration.

To minimize personal interference with the readers, Lin condenses para-texts to indispensable ones providing necessary background information and concise explanations to introduce Sun Tzu and his work and outline the main content and core concepts without personal assessment. This relieves the burden of understanding numerous and trivial supplanted materials, which on the other hand, makes the translation less academic and limits the scaffolding utility for academic research.

Facilitating the understanding of key concepts and terms is another requirement for Sun Tzu to speak for himself. Hence, Lin adopts a small number of footnotes and interlinear notes to reconstruct the historical, social and cultural context of “奇正 qi zheng”, “虛實 xu shi”,“五行 wu xing”, “九變 jiu bian” and other terms pivotal to the understanding of Sun Tzu.

Being composed 2,000 years ago, the work may conjure up ambiguities related to context, linguistic complexity and diachronic variations. Lin prudently deals with the polysemous phenomenon to relieve the burden of prospective readers. Take the high-frequency word term 地 di as an example, Lin translates “死生之地” as “a matter of life and death”, while puts the 地 in “地者, 高下、遠近、險易、廣狹、死生也”, “天地孰得” and “散 地、輕地” into “earth", "the advantage of earth" and "region" respectively.

To say it in Sun Tzu's own words makes it necessary to read been lines and dig out the covert information. Lin adopts embedded clauses to expound related concepts, situations and contents. For example, when it comes to terms like “通” related to military geography, Lin translates them into the format of "tong (通)- that which is accessible", improving semantic fullness by decreasing semantic loss in interlingua transmission. Another example is the translation of “勝者之戰人也, 若決積水於千仞之溪者, 形也”into “So great is the disparity of strength that a victorious army goes into battle with the force of an onrushing torrent which, when suddenly released, plunges into a chasm a thousand of fathoms deep. This is what we mean by disposition", keeping faith to the source text while adding vivid depiction to the onrushing situation of the torrent.

\subsection{Seeking for cultural understanding: reorient the Other and the Self}

Lin's translation is bestowed with the mission of providing a window for people interested in Sun Tzu throughout the world instead of targeting at a limited readership in the academia circle. Meanwhile, it shoulders the responsibility to eliminate the discrimination and misreading of Chinese culture as 栬道 mentioned in Minford's translation.

Lin swifts between Foreignization and Domestication strategies to fulfill the dual objectives.

The juxtaposition of original Chinese text with English translation itself is an endeavor to keep the cultural uniqueness and may be an attraction and facilitation to readers with Chinese language proficiency. Besides, he tries to eliminate the reading difficulty led by cultural blank or disposition through a combination of transliteration, word-for-word translation, Pin Yin, Chinese characters and annotations. There exist many Proper Names with vacancy of conceptual meaning in the target language like measurement words “鐘/石”. Lin puts them into "one zhong (tr.: 1,0000 litres)/ one dan (tr.: 60 kilos)" to arouse the recognition of them as cultural words peculiar to Chinese and aid rough transformation without interfering the discourse fluency. For terms with vacancy of historical connotations like “諸、龃”, Lin uses “Zhuan Zhu, Cao Gui and other heroes of ancient times" to eliminate the symbolic meaning of heroism. As for terms with disposition of connotations like “奇 正”的散地”, Lin puts them into “qi (奇) and zheng (正)”and “dispersive (san 散)”, guaranteeing the semantic fullness and reserving the Chinese flavor at the same time.

Realizing that too much uniqueness may be confronted with cultural shock or resistance, Lin adopts Domestication translation for most cases by replacing the source text with roughly equivalent counterparts in the English language. For example, while translating weaponry words like “馳車”““革車”and“帶甲”, Lin puts them into "light chariots", "heavy chariots" and "armored soldiers" respectively without expounding the external feature, material, composition or purpose as Sawyer does.

When it comes to “四帝 his four opponents”, “率然 the snake found on Mount Chang” and other words related to Chinese legendary, unlike Sawyer's thick translation, Lin tends to generalize or delete the cultural image through 
literal translation. It is possible that Lin considers them as obstacles for the western readers, the deletion of which does not entail pivotal loss to the source text, but opportunities to popularize related cultural elements eclipsed with such oversimplification as well, which certainly does not conform to the cultural mission expected from this translation.

\subsection{Keeping the true color: say it in Chinese way}

While falling short in its introduction, which is full of historical simplifications in its account of basic terminology, Lin's translation makes more adaptations of Modality and Cohesion at the lexico-grammatical level to improve readability of the translated discourse.

Lin translates some declaratives into imperatives to form epigrams. For example, he puts “知已知彼, 百戰不殆” into "Know your enemy and know yourself and you can fight a hundred battles without peril" with a strong sense of rhythm.

Lin attempts to create a kind of friendly interaction by switching the narrative perspectives. He uses interpersonal metaphor “I/We mean" to expound the connotations of concepts like“勢” and“形”,while making the discourse more interactive and reminding the reader of the unique cultural connotation as well.

He changes some imperatives to declaratives with "you" as the subject to soften the mood expression and adopts first singular "I" for many times, collocated with modal verbs "should/would", to exert influence on the reader implicitly while translating “勢者, 因利而制權也” and enhances the communicative effect of the translated text, ultimately facilitating the popularization of Sun Tzu culture as a whole.

Besides, Lin creatively applies emphatic sentences and inverted sentences to expound, comment and summarize the text. For example, by translating “凡此四軍之利, 黃帝之所以勝四帝也” into “It was such advantageous positioning of his troops in these four different situations that enabled the Yellow Emperor to defeat his four opponents", he adds the affirmation and comment of 利, which eases the reader's understanding.

Abbreviations abound in Chinese Classics which may give rise to ambiguity. Lin applies conjunctives including if, so, hence, therefore, thus, so as to, so that, as a result and so on to make the logic explicit, thus providing more clues for the readers.

As a whole, Lin's translation is more accurate in most cases due to the understanding advantage of Chinese culture, and sounds more exotic concerning key terms especially related with military geography. But it drags behind in providing necessary explanations and historical evidence for academic research, which greatly affects the acceptance among overseas readership (Li, 2015, p. 77-82).

\section{J.H. Huang: Digging deeper and articulating uniqueness}

As "for truly successful translating, biculturalism is even more important than bilingualism, since words only have meanings in terms of the cultures in which they function (Nida, 1993, p. 110)", it is ideal to have bilingual translators familiar with both the source culture and the target culture.

J.H. Huang, a translator and scholar is right the person desired for the translation of Sun Tzu: as an overseas Chinese, he is of high proficiency of both Chinese and English, being familiar with both cultures as well. Huang (1993) overtly expresses pride of Chinese culture and excels at re-contextualizing Sun Tzu with rich para-texts, strong reader-awareness, through explanation of cultural elements and exhaustive probing into the diachronic changes of language and characters with many novel and distinct viewpoints proposed, which altogether adds to the necessity of reviewing the work in this article.

\subsection{Being academic: stand closer to Sun Tzu and his time}

Huang believes that Sun Tzu and his masterpiece have exerted great influence on numerous historical personages throughout the history and continues to penetrate to various fields apart from military. He spent seven years studying the Linyi texts of Sun Tzu and repeatedly refers to other versions like the Song edition with the attempt to get closest adherence to the source text and culture.

Huang applies thick translation as well and resort to rich para-texts to re-contextualize Sun Tzu. The 20-page pre-text introduction outlines the story of Sun Tzu, the cardinal concept of Sun Tzu's Art of War and the discovery of the linyi bamboo-slat text.

To enhance readability, the translation is sparely footnoted with translator's summaries of each passage juxtaposed on the left hand margin, while leaving detailed chapter-to-chapter annotations far outweighs the translation itself in length to the second part of the book.

Huang explains key concepts like “計 ji”、“兵 bing” and “勢 shi”. Then, he lists different views towards certain 
content and validates his own translation. For example, he decides to translate “將聽吾計, 用之必勝, 留之; 將不聽吾計, 用之必敗，去之” into “When commanders heed our surveys and are appointed, victory is assured; retain them; When commanders do not heed our surveys and are appointed, defeat is assured; dismiss them" after pondering on the three prevalent viewpoints. He provides explanations and comments on specific jargons, Proper Names, commentaries and different original text of Sun Tzu as well.

In the para-texts, Huang cites and quotes over 30 kinds of Chinese Classics including Zuozhuan, Shiji, Sun Bin bingfa, Shuowen and Liji and resorts to historical figures like Qi Jiguang, scholars like Wang Yinzhi and so on for detailed explanations.

The introduction and material supplement are constructive to reconstruct the historical and culture context of Sun Tzu and his work.

Meanwhile, as the ultimate purpose of translation is for communication, it is inevitable that the translator should have a good reader-consciousness. Huang tries to make his translation reader-friendly mainly through three ways. He adopts Domestication strategy, replacing many terms with those in the western world to cater to the expectancy and habits of potential readers. He adjusts the layout of the translation as mentioned previously. Also, he repeatedly refers to Griffth, Giles and other translators to broaden the reader's horizon.

\subsection{Being confident and proud: reserve the cultural images}

Sun Tzu's work contains many cultural images and concepts like 率然 shuairan, 四帝 sidi, 天 tian, 栬道 guidao and so on rooted in ancient Chinese society, which entails difficulty in understanding on the part of western readers unfamiliar with Chinese culture.

Realizing their importance in cultural communication, Huang seizes the opportunity to popularize such cultural images and concepts through thick translation with evidence sought out from relevant Chinese Classics.

Take “故善用兵者, 譬如率然; 率然者, 常山之蛇也” as an example: 率然 is a kind of snake found in 常山, being rather flexible and can protect its head with the tail and vice versa. Sun Tzu means that generals should be flexible enough as 率然 does and it has become a widely received cultural image to praise the subtlety and superb flexibility in military operations. Huang puts the sentence into "Those sophisticated at commanding battle arrays are like a shuairan. The shuairan was a serpent at Mount Heng...". Through transliteration, he solves the problem of term equivalence, and noticeably, he translates 常山 into Mount Heng which is impossible without serious academic studying, as evidence shows that 常山 is indeed 恒山 due to historical reasons. However, equals 率然 with a serpent entails pejorative connotation. Besides, it is unlucky that Huang does not point out the legendary origin of 率然 as Minford does.

Huang is clear about the tradition of using concrete numbers for rough counting, hence he translates 四帝 into “all of his enemies". Meanwhile, he adds detailed annotation, pointing out that 四帝 may refer to enemies from the four terrains mentioned previously or enemies from the four directions. Besides, he relates the legend in the appendix and critically states that the legend occurred later than Sun Tzu's Art of War, hence including it in the work is unreasonable, which validates the generalization of 四帝 into all enemies at the same time.

As for 天 tian, Huang has full knowledge of its philosophical and dialectical connotation, hence using "cyclic natural occurrences/in the world/the whole world/ worldwide/all the countries" instead of terming it with "Heaven" as Sawyer and Minford do. The avoidance of inflicting religious flavor on Sun Tzu stands closer to the source text.

“詭道 guidao" has aroused controversial interpretations in different translations. Although few translators go astray so far as Minford does, most of them avoid deep explorations. Huang deems it inappropriate to judge 詭 道 from the perspective of ethical virtue, and testifies the essence is about change citing Huang Zhen and other scholars, which leads to his translation "unconventional means".

His deals with culture-loaded terms like 旌旗 jingqi, 丘牛大車 qiuniu dache and so on in similar ways. Overall, Huang excels at providing evidence in annotations and does a good job in preserving the cultural image.

\subsection{Keeping the digging: exhibit archeological flavor}

As a researcher on Sun Tzu instead of a mere literary translator, Huang strives for the concrete evidence to get closer to the masterpiece, bestowing a flavor of archeological endeavor to his translation.

Huang explores the diachronic change of linguistic aspects in particular, including that of 計 ji, 時 shi, 部曲 buqu，將軍 jiangjun，卒 zu，廟 miao，賓客 binke，百姓 baixing and many others.

Take “四五者,不知一,非霸王之兵也” as an example. 四五 conjures up ambiguity among different translators. 
Huang translates it into "these several things"and expound it in the annotation with evidence from Sun Bin bingfa and Mozi from three aspects: In pre-Qiu period, 四五. was usually used for rough counting; it resembles the wording of 三五 in contemporary Chinese; it is unreasonable for commentators, like Caocao and Zhangyu, to hold that 四五 refers to the nine terrains by combing four and five.

When it comes to the translation of 廟算 miaosuan, Huang traces the origin of 廟, discusses its different connotations and puts it into "ancerstral temple", while arguing for the necessity to translate 廊廟 langmiao into “court”. Similarly, Huang fully explores the connotation and changes of concepts like 霸王 bawang, 五聲 wusheng, 五色 wuse and 五行 wuxing and so on.

Besides, Huang makes comparisons among Linyi text, Sakurada version, Song version and the Seven Military Classics for many times. For example, he points out that there is no “焚舟破釜 burns his boats and breaks his pots" in Linyi text. By doing so, Huang facilitates the comparison of different versions and validates his own translations with solid evidence.

\subsection{Being ingenious: try unique translations}

Just as David Barno wrote in the preface "much of the Western military thought of the twentieth century was derived from Carl von Clausewitz and his timeless work On War, Huang's new translation is helpful to break the conventional thinking mode.

Huang's translation sparks with many ingenious viewpoints, such as translating 天 tian and 詭道 guidao into cyclic natural occurrences and unconventional means respectively.

However, there exists a controversial example, i.e. Huang translates “不爭天下之交, 不飬天下之權” into “competing for worldwide alliances and developing worldwide influences", as he argues that 不 is an auxiliary word that indicates mood. This interpretation is rather different from most translations including that by Giles, Griffth, Roger Ames and the other three translators discussed previously.

As a matter of fact, no unanimously accepted view has been reached even in the Chinese academia field concerning this sentence. Therefore, Huang's new interpretation is acceptable as supported by historical evidence and materials, and will possibly stimulates renewed thinking of the statement from other perspectives.

Nothing stays the same but change. It is the same case with the interpretation of Classics like Sun Tzu's Art of War as the context does not keep unchanged. Therefore, no translation can be perfect in terms of linguistic, philological and historical competence, just as shown in the four translations reviewed in this article. In any case, the pivotal principle should be born that breach or misreading of core concepts must be avoided to the uttermost in order to advance the reputation of Sun Tzu and his masterpiece to the English-speaking readers.

\section{Acknowledgments}

This paper is supported by "Natural Language Processing from the Perspective of Functional Linguistics" Project (NCET-10-0228) sponsored by Ministry of Education of The People's Republic of China.

\section{References}

Cheng, L. (鄭鹿). (1946). The Art of War: Military Manual Written Cir. 510 B.C./Original Chinese Text Appended. Shanghai: Word Book Co., Ltd.

Griffth, S. B. (1963). Sun Tzu: The Art of War. Oxford: Clarendon Press.

Huang, J. H. (tr.). (1993). The Art of War (SunTzu). New York: HarperCollins Publishers.

Li Ning. (2015). On the Overseas Reception of Lin Wusun's English Version of The Art of War. Shanghai Journal of Translators, (2), 77-82.

Lin, Wusun. (2001). Sunzi: The Art of War; Sun Bin: The Art of War. Beijing: Foreign Languages Press.

Luo, Zhiye (羅志野). (2002). 100 Sun Tzu's The Art of War. Beijing: China Translation \& Publishing Minford, Minford, J. The Art of War. New York: Penguin Group.

Nida, E. A. (1993). Language, Culture, and Translating. Shanghai: Shanghai Foreign Language Education Press.

Roger T. Ames. (2002). Harmony but not sameness: Comparative Philosophy and Western Communication. Beijing: Beijing University Press.

Sawyer, R.D. (1994). The Art of War. Boulder: Basic Books.

Tao , Hanzhang (陶漢章). (1987). Sun Tzu: The Art of War. New York: Sterling Publishing.

Yuan, Shibin (袁仕斌). (1987). Sun Tzu's Art of War: the Modern Chinese Interpretation. New York: Sterling 
Pub Co Inc.

\section{Copyrights}

Copyright for this article is retained by the author(s), with first publication rights granted to the journal.

This is an open-access article distributed under the terms and conditions of the Creative Commons Attribution license (http://creativecommons.org/licenses/by/4.0/). 